\title{
Hangeul (Korean alphabet) Notation Method based on Hunminjeongeum, for the Pronunciations of [sh], [zh], and [ch] in Chinese Language
}

\author{
Sukyung Park ${ }^{1}$, Mun-Koo Kang ${ }^{2}$ \\ ${ }^{1}$ Graduate Student, Department of English Education, Kongju National University, Korea, \\ imunite@nate.com \\ ${ }^{2}$ Professor, Department of English Education, Kongju National University, Korea, \\ kangmunkoo@hanmail.net
}

Corresponding author: Mun-Koo Kang

\begin{abstract}
From the perspective of Chinese learners, intonations and pronunciations are a difficult task in learning Chinese language. Thus, there has been an increase in the need for research studies on the effective methods of learning the intonations and pronunciations of Chinese language simultaneously, and many research studies have been carried out. Recently, research studies on the learning methods, which can enable people to more effectively learn Chinese language by presenting the 'Chinese language pronunciation notation method using Hangeul (Korean alphabet)', rather than the Roman alphabetic notation, in accordance with the demands of Chinese language learners, have been attempted. However the existing notation methods have the problem of aggravating the confusion of the Chinese language learners by being presented in extremely diversified, incoherent formats. In particular, Hangeul notations for Chinese pronunciations, [sh], [zh], and [ch], which are the retroflex consonants, have been presented in various ways, causing excessive confusion for Chinese language learners. Therefore, there is a need to establish a unified notation method for the [sh], [zh], and [ch] pronunciations in Chinese language. Meanwhile, the semi-dental consonant $(\Delta)$ of Hangeul, presumed to have disappeared in the mid to latter part of the 16th century after the creation of Hunminjeongeum, has the pronunciation shape among the Hangeul letters closest to the pronunciation of the retroflex consonant of Chinese language. Therefore, it is deemed to be more useful to notate the [sh], [zh], and [ch] pronunciations in Chinese language by using semi-dental consonant of Hangeul. In addition, since principle standards for the Hangeul notation method for [sh], [zh], and [ch] pronunciations in Chinese language have not been defined, there is a need to standardize the Hangeul notation method by presenting the definitions thereof. It is deemed necessary to consider not only the mutually related functional perspectives, including the pronunciation and notation formats, but also the fundamental principle of the creation of Hunminjeongeum as the principle standard for such Hangeul notation method. In this survey, the researchers reviewed the existing research methods on the Hangeul notation method for the pronunciation of [sh], [zh], and [ch] in Chinese language. As a result, the researchers found that it is necessary to establish principle standards for phonetic notations and subsequently suggested three principle standards for Hangeul notations: (i) Ease of recognition by Chinese language learners, (ii) Usefulness within a digital environment, and (iii) Fidelity to the basic principles of Hunminjeongeum. Based on these principle standards, the researchers would like to suggest Hangeul notation method for pronunciations of [sh], [zh], and [ch] in Chinese language.
\end{abstract}

Keywords: Hangeul Notation, Chinese Language, Hunminjeongeum, Retroflex Consonant, [sh], [zh],

Received: August 03, 2020; $1^{\text {st }}$ Review Result: September 21, 2020; $2^{\text {nd }}$ Review Result: November 06, 2020 Accepted: December 28, 2020 


\section{Introduction}

Recently, China has been achieving rapid economic growth to the extent of its status being raised as one of the G2 member counties, and there has been marked and continued increase in the need to study Chinese language as the interactions of China with all the countries in the world are also increasing rapidly. Accordingly, a wide range of research efforts on the study methods to more effectively learn and master Chinese language are being carried out. From the linguistics perspective, Chinese language is an ideogram based on Chinese characters, which are a representative hieroglyph and cannot be read and vocalized without the use of phonetic symbols, that is, Hanyu Pinyin. In addition, due to the existence of countless homonyms, intonations, that is, pitches of sound, and prosodemes of long and short sounds, all have been used for explicit distinction of the meanings of words. Thus in order to distinguish the meanings and phonetic values of Chinese language, it is necessary to notate intonation and pronunciation, that is, Hanyu Pinyin, for each of the characters by differently distinguishing them. Therefore, there has been the increase in the need for research studies on the effective methods of learning the intonations and pronunciations of Chinese language simultaneously and many studies have been carried out [1-3].

In recent years, research studies on the learning methods, which can enable people to more effectively learn Chines language by presenting the 'Chinese language pronunciation notation method using Hangeul (Korean alphabet)', rather than the Roman alphabetic notation in accordance with the demands of the learners of Chinese language, have been attempted in diversified formats [4-6]. However, only after the reinstatement and re-designation of the Hangeul Proclamation Day as a national holiday, researchers began to pay attention to the importance of the Hangeul notation method that can substitute the Roman alphabet letters.

Won Soo Jeong (2009) in relation to the method of Chinese language pronunciation notation by using Hangeul, asserted that Hangeul characters are more outstanding than the Hanyu Pinyin letters (Roman alphabet letters) as the ideal phonetic symbols to notate Chinese language[7]. Meanwhile, Eun Joo Shin, et al. (2020) asserted that the unified proposal for Hangeul orthography currently used has a difference in the phonetic values from the notation methods used at the time of the invention of Hunminjeongeum, which was capable of expressing all sounds. Therefore, she asserted the need to restore the characters that have disappeared thereafter as there exist sounds that modern Hangeul cannot express in order to more properly present the phonetics of Chinese language. For example, she presented a different solution for the notation method for [f], [r], [sh], [zh], and [ch][8]. In particular, although diversified notation methods for retroflex consonant pronunciations in Chinese language including [sh], [zh], and [ch] have been proposed, such existing notation methods have been presented by considering only their functional aspects based on the ease of inputting them under the digital environments or their accessibility of pronunciation, and they have limitations from the perspective that there are no theoretical grounds regarding the basic principles of Hunminjeongeum. In addition, the existing notation methods have the problem of aggravating the confusion of the Chinese language learners by being presented in extremely diversified formats without coherence. Therefore, there is a need to establish a unified notation method for the [sh], [zh], and [ch] pronunciations in Chinese language, as well as the need to set the fundamental standardization of the aforementioned pronunciations with such a unified notation method.

Accordingly, this study will review the existing notation methods presented for the [sh], [zh], and [ch] pronunciations, which have become problematic in notating the pronunciations of Chinese language, by using Hangeul, and also propose a notation method that strictly adheres to the basic principles of Hunminjeongeum as the unified notation method. 


\section{Preceding Studies}

\subsection{Hangeul Notation of [sh], [zh], and [ch] Pronunciations in Chinese Language}

Won Soo Jeong (2009), in his paper 'A Study on the Educational Method for Chinese Language Using Korean Alphabets', presented the method of notating the pronunciations for 2,500 commonly used Chinese characters with Hangeul in order to more precisely notate the pronunciations of Chinese language by using Hangeul. As such, he notated [sh], [zh], and [ch] with ' 0 人, , ' $0 \boldsymbol{z}$, and ' $0 \overline{\boldsymbol{z}}$, , respectively[7]. Further, Won Soo Jeong (2008) developed the 'Apparatus for Inputting Korean Character as Chinese Phonetic Transcription and Method Thereof', which could actualize the abovedescribed method in a digital environment[9]. In the above method, [sh], [zh], and [ch] in Chinese could be expressed as ' $0 \mathcal{\lambda}$, , ' $0 \boldsymbol{x}$, and ' $0 \overline{\boldsymbol{\lambda}}$, , respectively, by using a means of converting them to a serial signal or a parallel signal. In addition, Sung Ho Beck (2011) developed the 'System and Method Displaying Hangeul Phonetic Symbols Including Chinese Language Characters using Information of Tone and Learning Methods using Hangeul Phonetic Symbols, Including Chinese Language Characters using Information of Tone', which could express [sh], [zh], and [ch] in Chinese as Hangeul [10].

Meanwhile, Eun Joo Shin, et al. (2020) pointed out in her paper 'Apparatus and Method for Inputting Chinese Based on Hunminjeongeum Using Korean Input Keyboard' that the aforementioned notation methods generate the problem of ambiguity on whether they are inputting of final consonant ' $O$ ' of the front syllable and initial consonants '人', ' $\boldsymbol{~}$ ' and '大', or whether they are double

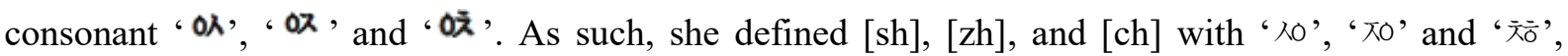
respectively[8]. In addition, she introduced diversified notation methods for notation of the [sh], [zh], and [ch] pronunciations as illustrated in the Table 1 below[8][11].

[Table 1] Various Claims about Hangul Notations for [sh], [zh], and [ch]

\begin{tabular}{|c|c|c|c|}
\hline Pronunciation & \multicolumn{3}{|c|}{ Various notation claims by pronunciation } \\
\hline$[\mathbf{s h}]$ & 人す & $\Delta$ 人 & 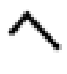 \\
\hline [zh] & ㅉㅎ & $\Delta$ 万 & 下 \\
\hline [ch] & 大む & $\Delta$ 大 & $\leftarrow$ \\
\hline
\end{tabular}

(Source: E. Shin, J. Choi, S. Lim, "Apparatus and Method for Inputting Chinese Based on Hunminjeongeum Using Korean Input Keyboard", Journal of Korea Multimedia Society, Vol. 23, No. 4, p.550, 2020.)

The fact that there are diversified proposals for the notation methods for [sh], [zh], and [ch] pronunciations in Chinese language is evidence that there is no single appropriate notation method and differing standards for the notation method. That is, majority of the proposals for the newly created character design that previously did not exist in Hunminjeongeum were either based on the purpose of making inputting of the characters easier under the digital environment or considered only the functional aspects as in the case of the proposal based on pronunciation. In addition, standards for the proposed notation methods are not unified and the notation methods themselves are proposed in 
diversified formats including the utilization of chronological notation method and modified letters etc. As pointed out above, these notation methods, having been proposed in highly diversified formats without coherence, are generating the problem of aggravating confusion in the Chinese language learners.

\subsection{Phonetic Values of Semi-dental Consonant $(\Delta)$ in Hangeul}

Hee Sun Yun (2009), in her paper 'A Diachronic Study on the Change of $/ z /(\Delta)$ in the Late Middle Korean Period', asserted that Sung Nyong Lee (1956) and Gwang Woo Nam (1962) classified the semi-dental consonant $(\Delta)$ as $[\mathrm{z}]$ and $[\mathrm{s}]$, respectively, in the process of making considerations on the history of research on the phonetic values of semi-dental consonant $(\Delta)$ presumed to have disappeared in the mid to latter part of the 16th century following the creation of Hunminjeongeum in the 15th century. Moreover, she asserted that since ' $\Delta$ ' is stipulated as a 'semi-dental consonant' in Hunminjeongeum, ' $\Delta$ ' can be presumed to be a voiced consonant pronounced at the position of alveolus that is the same as those of '人, $\boldsymbol{X}$ and $大$ ', etc[12].

Meanwhile, Dae Jong Park (2019), in his writing on the phonetic values of the semi-dental consonant $(\Delta)$, asserted that semi-dental consonant refers to the sounds for which half is a dental sound while the other is a lingual sound and that the image of the semi-dental consonant is modeled after the shape of the tongue and teeth on the basis of the interpretation of the Hangeul academic circle on Chapter 2, “牛舌音己, 牛齒音 $\Delta$, 亦象舌齒之形”of the 'Hunminjeongeum Haerye'. In addition, he asserted that when pronouncing ' $\curlywedge$ ', the tip of the tongue touches the back of the lower teeth, while the tongue is detached from the lower teeth and is raised to the upper gum when pronouncing semidental consonant, as in the case of pronouncing lingual consonants such as ' $L$ and $\sqsubset$ '. He further asserted that semi-dental consonant $(\Delta)$ produces sound corresponding to that of $[\mathrm{s}]$ and proposed to notate $[\mathrm{z}]$ with ' $\square$ ' and lingual consonant type '大' with ' $\Delta$ ' [13]. However, there is currently no way of accurately confirming the phonetic value of semi-dental consonant $(\Delta)$ at the time of the creation of Hunminjeongeum and, for such reason, it is unavoidable that there are highly diversified different assertions on the phonetic value of the semi-dental consonant $(\Delta)$. Nonetheless, there is no significant difference in opinion on the fact that the semi-dental consonant $(\Delta)$ is a voiced consonant that is distinguished from the voiceless consonant ' $\lambda$ ' and similar to the retroflex consonant pronunciation in Chinese language.

From such perspectives, it is deemed that the semi-dental consonant of Hangeul can play important role in the Hangeul notation method for [sh], [zh], and [ch] pronunciations. That is, semi-dental consonant of Hangeul has the pronunciation shape among the Hangeul letters closest to the pronunciation of the retroflex consonant of Chinese language. Therefore, it is deemed to be more useful to notate the [sh], [zh], and [ch] pronunciations in Chinese language by using semi-dental consonant of Hangeul than the method of using letters such as '人', '大' and '大' from the phonetics perspective.

\section{Hangeul notation method based on Hunminjeongeum, for the pronunciations of [sh], [zh], and [ch] in Chinese language}

\subsection{Standards for the Hangeul Notation Method for [sh], [zh], and [ch] Pronunciations}


As examined above, since principle standards for the Hangeul notation method for [sh], [zh], and [ch] pronunciations in Chinese language have not been defined there is a need to standardize the Hangeul notation method by presenting the definition thereof. As such, it is deemed necessary to consider not only the mutually related functional perspectives including the pronunciation and notation format, etc. but also the fundamental principle of the creation of Hunminjeongeum as the principle standards for such Hangeul notation method. Accordingly, this study proposes the following principle standards for the Hangeul notation method for [sh], [zh], and [ch] pronunciations: first, ease of recognition by Chinese language learners, second, usefulness under digital environment and third, fidelity to the basic principles of Hunminjeongeum.

\subsubsection{Ease of Recognition by Chinese Language Learner}

'Ease of recognition by Chinese language learner' means that the learners can clearly recognize that Hangeul notation format can be clearly be distinguished as 'retroflex consonant' that expressed by [sh], [zh], and [ch] pronunciations in Chinese language in order to easily determine clear distinction from the pronunciation of '人', ' $\boldsymbol{~}$ ' and '大', which are voiceless consonants in Hangeul. That is, the Hangeul notation presented for the [sh], [zh], and [ch] pronunciations in Chinese language, by having clarity in order for Chinese language learner to easily assess that the notation is the retroflex consonant pronunciation of Chinese language, must enable the learner to attempt pronunciation of retroflex consonant intentionally by looking at the Hangeul notation presented.

\subsubsection{Usefulness Under Digital Environment}

'Usefulness under digital environment' means that inputting of the Hangeul notation format presented must be easy by using computer or mobile phone, and there must be no problems in allocation of the Unicode and realization of the font. Since the users who are used to quick communication through SNS, etc. in the modern society recognize the method of conveying the maximum meanings with the minimum input into the terminal units as the most effective method, there is a need for the Hangeul notation method propose to have the usefulness under the digital environment that complies with such demands of the users.

\subsubsection{Fidelity to the Basic Principles of Hunminjeongeum}

What must not be overlooked in considering the principle standards for notating the pronunciation of Chinese language with Hangeul is that the proposed Hangeul notation is aimed only at effectively notating the pronunciation of Chinese language and, as such, must not ignore the pronunciation principles or creating principles of Hangeul. In other words, if the Hangeul notation method is developed on the basis of the functional aspects of the pronunciation and format, it is inevitable that notation methods will be further mass-produced with increased difficulties in unification thereof. In addition, there is concern for damaging the originality of Hangeul, which is the foundation for notating pronunciation of Chinese language with Hangeul. Furthermore, since the standardization of Hangeul notation with the notation method that is sincere to the basic principles of Hunminjeongeum including the pronunciation or creating principles of Hangeul is a means of having the excellence of Hangeul been known more widely, there is a need to sufficiently consider such factors.

\subsection{Review of the Existing Hangeul Notation Methods for [sh], [zh], and [ch] Pronunciations}

\subsubsection{Chronological Notation Method}

What must not be overlooked in developing the method of notating Chinese language pronunciation 
with Hangeul is that the proposed Hangeul notation must not stop at simply reflecting the pronunciation notation. As examined in the preceding studies, a diverse range of notation methods have been presented to notate the [sh], [zh], and [ch] pronunciations and the reviews thereof are as follows:

According to the notation method of Won Soo Jeong (2009), [sh], [zh], and [ch] were notated as

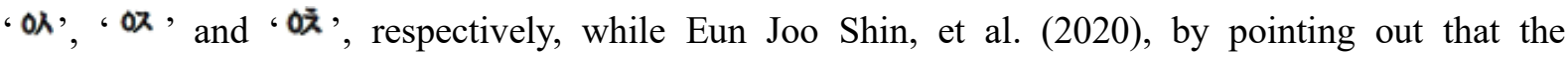
aforementioned notation methods generate the problem of ambiguity on whether they are inputting of final consonant ' $O$ ' of the front syllable and initial consonants '人', '大' and '大', or whether they are

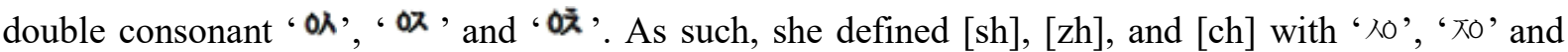
“六”', respectively. However, all the notation methods such as above are using chronological notation, which is deemed to have problem from the perspective of the 'ease of recognition by Chinese language learner'. That is, when the Chinese language learners see the chronological notation method such as ' $O \curlywedge$ ', their interpretation would be that ' $\curlywedge$ ' needs to be pronounced by recalling its phonetic value but perceive ' $O$ ' notate thereafter only as a command to pronounce it only as a retroflex consonant and ' 10 ' is only a notation method that changed the order of the letters. Same applies to the notation method of ' 'रt'. Here, since ' $ᄒ$ ' is only a retroflex consonant and is close to a command to pronounce.

In addition, in the case of ' $\Delta \curlywedge$ ', ' $\Delta$ ' is interpreted only as a command to pronounce it as a retroflex consonant. In other words, since the notation methods used as chronological notation methods have the format of having attached command ( $O, \bar{o}, \Delta$ ) to pronounce as a retroflex consonant to each of the phonetic values, they have the fundamental limit of difficulties in easy recognition by the Chinese language learners. In addition, it would be difficult to interpret that such notation method sincerely complied with the pronunciation principles or creating principles of Hangeul in terms of the "extent of fidelity towards the basic principles of Hunminjeongeum'. The structure of pronunciations and problems of the chronological notation method are summarized and illustrated in Table 2 as follows:

[Table 2] Structure for Pronunciation and Problems of the Chronological Notation Method

\begin{tabular}{|c|c|c|}
\hline Pronunciation & \multicolumn{2}{|c|}{ Chronological Notations } \\
\hline [sh] & 人す & $\Delta$ 人 \\
\hline [zh] & ススす & $\Delta$ 大 \\
\hline [ch] & 大む & $\Delta$ 大 \\
\hline $\begin{array}{l}\text { Structure for } \\
\text { Pronunciation }\end{array}$ & Phonetic value + Instruction notation ( & Instruction notation $(\Delta)+$ Phonetic value \\
\hline Problems & $\begin{array}{l}\text { 1. Not easily recognized to pronounce it as } \\
\text { 2. Low fidelity towards the basic principle }\end{array}$ & $\begin{array}{l}\text { flex consonant } \\
\text { nminjeongeum }\end{array}$ \\
\hline
\end{tabular}




\subsubsection{Jeongchieum (正齒音) Notation Method}

The Notation method such as ' $\wedge$ ' of the single-letter notation format can be advantageous from the perspective that there are no problems of ease of recognition by Chinese language learners. However, although notation method in such format uses the modified letters of the old Hangeul letters of the past, according to the definition related to Jeongchieum, 'it is a sound made with the tip of the tongue touching the lower gum' and there exists the differences in the materialization of the sound and the principle articulation method, which is the opposite of the pronunciation method for retroflex consonant of Chinese language that requires rolling up of the tongue deeper into the mouth and adhering the tongue to the palate. As such, it ignores the existing pronunciation principles of Hangeul, thereby leading to the understanding as a notation method with fundamental problems in terms of the 'level of fidelity towards the basic principles of Hunminjeongeum'. The letter shape of single notation of Jeongchieum and the problems of single notation of Jeongchieum are summarized and illustrated in Table 3 as follows:

[Table 3] Problems of Single Notation of Jeongchieum

\begin{tabular}{|c|c|}
\hline Pronunciation & Notation of Jeongchieum \\
\hline \hline$[\mathbf{s h}]$ & 丈 \\
\hline$[\mathbf{z h}]$ & 大 \\
\hline$[\mathbf{c h}]$ & $\begin{array}{l}\text { Inconsistent with pronunciation principles of Hunminjeongeum } \\
\rightarrow \text { Low fidelity towards the basic principles of Hunminjeongeum }\end{array}$ \\
\hline \hline Problems & \begin{tabular}{c} 
\\
\hline
\end{tabular} \\
\hline
\end{tabular}

\subsubsection{Hangeul Notation Method for [sh], [zh], and [ch] Pronunciations using Semi-dental Consonant $(\Delta)$}

Although the notation method using semi-dental consonant $(\Delta)$ was presented by Dae Jong Park (2019) as an example of materializing pronunciation for [z], the semi-dental consonant is composed of half of dental sound and lingual sound, thereby having the phonetic value most similar to the retroflex consonant pronunciation of Chinese language. As such, it is evaluated to be sincere to the creating principle of Hangeul even in terms of the notation method.

First, from the perspective of pronunciation, although there are diversified opinions on the pronunciation of the semi-dental consonant $(\Delta)$ as examined above, it is closed to being a retroflex consonant as a voiced consonant distinguished from the voiceless consonant, '人'. Accordingly, it has the advantage of easy recognition by Chinese language learners as a retroflex consonant [sh] in the format of single-letter notation.

Second, from the perspective of the configuration, since ' $\Delta$ ', ' $\square$ ' and ' $\Delta$ ' have similar configurations as '人', ' $\boldsymbol{~}$ ' and '大', respectively, there is the advantage of the ease with which the Chinese language learners can recognize them as [sh], [zh], and [ch], respectively, and pronounce them as retroflex consonants. Furthermore, by applying the producing principle that is the same as that 
of the Hunminjeongeum in which a stroke is added to ' $\boldsymbol{~}$ ' to produce ' $\boldsymbol{~}$ ', and a stroke is added to ' $ス$ ' to produce '大', ' $\square$ 'is produced by adding a stroke to the semi-dental consonant ' $\Delta$ ', and ' $\Delta$ ', is produced by adding a stroke to ' $\square$ '. Accordingly, it can be seen that they have been made by sincerely adhering to the producing principles of Hunminjeongeum. Meanwhile, restoration and use of the lost semi-dental consonant $(\Delta)$ also has the advantage of providing substantial assistance in rediscovering the excellence of Hunminjeongeum.

\section{Results and Discussion}

As reviewed above, it has been presented that the method of notating the [sh], [zh], and [ch] pronunciations of Chinese language with Hangeul by utilizing a semi-dental consonant has excellence in terms of the 'ease of recognition of retroflex consonant by Chinese language learner' as well as the 'extent of fidelity towards the basic principles of Hunminjeongeum'. Therefore, it would be desirable to standardize the Hunminjeongeum-based Hangeul notation method for [sh], [zh], and [ch] pronunciations by notating [sh] with ' $\Delta$ ', [zh] with ' $\square$ ' and [ch] with ' $\Delta$ '.

Meanwhile, in relation to the perspective of the 'usefulness under digital environment', semi-dental consonant $(\Delta)$ is a letter to which a Unicode $(317 \mathrm{~F})$ has been allocated, it is possible to realize the format of notating ' $\square$ ' and ' $\Delta$ ' by using 'Alt' key or 'Fn' key. As another method, it is possible to

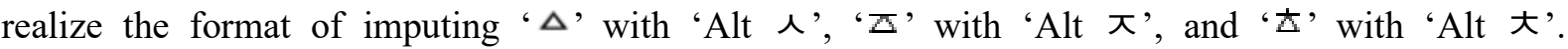
Therefore, since inputting the letters easily can be performed through such methods, Hunminjeongeum-based Hangeul notation method for [sh], [zh], and [ch] pronunciations by utilizing semi-dental consonant would have no significant problem from the perspective of the 'usefulness under the digital environment'.

In summary of the contents discussed above, the method of notating [sh] with ' $\Delta$ ', [zh] with ' $\square$ ', and [ch] with ' $\Delta$ ' have the following features. First, since it is in a single-letter format, there is the advantage of the Chinese language learner easily recognizing them as [sh], [zh], and [ch], respectively, and pronouncing them as retroflex consonants. Second, since it can be easily inputted under digital environment in the method of using the Unicode allocated to semi-dental consonant or by concurrently using 'Alt' and '人, 大, 大' keys, respectively, there would be no significant problem in terms of the 'usefulness under the digital environment'. Third, it is evaluated as the most outstanding method in terms of the 'level of fidelity towards the basic principles of Hunminjeongeum' since the lost semidental consonant $(\Delta)$ is restored for the use and created by using the principle of adding strokes, which is a basic principle of Hunminjeongeum. Therefore, it is desirable to standardize Hunminjeongeum-based Hangeul notation method for [sh], [zh], and [ch] pronunciations with such notation method. The features of the Hangeul notation method based on Hunminjeongeum are summarized and illustrated in Table 4 as follows:

[Table 4] Hangeul Notation Method based on Hunminjeongeum, for the Pronunciations of [sh], [zh], and [ch]

\begin{tabular}{|c|c|}
\hline Pronunciation & Hangeul Notation \\
\hline \hline$[\mathrm{sh}]$ & $\Delta$ \\
\hline$[\mathrm{zh}]$ & $\triangle$ \\
\hline
\end{tabular}




\begin{tabular}{|c|ll|}
\hline$[\mathrm{ch}]$ & \multicolumn{1}{|c|}{ 士 } \\
\hline \multirow{3}{*}{ Features } & 1. & Easily recognized to pronounce it as a retroflex consonant \\
& 2. & Useful within a digital environment \\
& 3. & High fidelity towards the basic principles of Hunminjeongeum \\
\hline
\end{tabular}

\section{Conclusions}

This study reviewed the existing notation methods presented for [sh], [zh], and [ch] pronunciations, which have raised the issues of the notation method for the pronunciation of Chinese language by using Hangeul. The existing notation methods were presented on the basis of the perspectives of the ease of inputting the letters under the digital environment and accessibility to pronunciation. As such, they have been presented by considering only their functional perspectives, thereby having the limitation of having no theoretical grounds for the basic principles of Hunminjeongeum, etc. Moreover, they have been presented without clear principle standards, thereby generating the problem of aggravating the confusion in the Chinese language learners. Accordingly, this study proposed 'ease of recognition by the Chinese language learner', 'usefulness under digital environment' and 'the level of fidelity towards the basic principles of Hunminjeongeum' as the 3 key principle standards for Hangeul notation method for [sh], [zh], and [ch] pronunciations.

As the results of the review made on the basis of such principle standards, the notation method that utilizes semi-dental consonant $(\Delta)$ has the phonetic value most similar to the retroflex consonant pronunciation of Chinese language and is highly sincere towards the creating principles of Hangeul. On the basis of these findings, the means of standardizing Hunminjeongeum-based Hangeul notation method for [sh], [zh], and [ch] pronunciations by notating [sh] with ' $\Delta$ ', [zh] with ' $\square$ ', and [ch] with ' $\triangle$ ' has been proposed. In addition, since semi-dental consonant $(\Delta)$ is a letter to which a Unicode (317F) has been allocated, it was presented in this study that the method of notating ' $\square$ ' and ' $\Delta$ ' by using 'Alt' and 'Fn' keys, respectively, and inputting ' $\Delta$ ' with 'Alt $\curlywedge$ ', ' $\square$ ' with “Alt $\boldsymbol{~}$ ', and ' $\Delta$ ' with 'Alt 大' can be realized.

As discussed above, principle standards for the Hangeul notation method for [sh], [zh], and [ch] pronunciations in Chinese language have not been defined. As such, there is a need to standardize the Hangeul notation method by presenting the definitions thereof. It is also emphasized that there is a need to consider not only the functional perspectives including pronunciation and configuration, etc. but also the fundamental principles of the creation of Hangeul as the principle standards for such Hangeul notation method. In the process of conducting this study, it was possible to perceive the sense of crisis and urgency that the diversified efforts that have been put in thus far to substitute Roman alphabets by notating the pronunciation of Chinese language by using Hangeul could become futile unless the standardized Hangeul notation method is defined and established as soon as possible. Although the development of diversified Hangeul notation methods for notation of the pronunciation of Chinese language is a desirable phenomenon, there also is the aspect in which such diversity is acting as a factor that aggravates the confusion in the Chinese language learners. As such, it is deemed necessary for all the researchers to recognize that we are at the moment that requires the unification of the existing diversified notation methods into a standardized notation method through sufficient reviews thereof, and to solve the relevant and ensuing problems. 


\section{References}

[1] H. Song, A Study on the Use of Hanyu Pinyin in the Education of Pronunciation and Translation in the Chinese Language, The Journal of Interpretation and Translation Education, (2004), Vol.2, No.2, pp.61-70.

[2] A. Shin, Several Proposals on Chinese Pronunciation Education using Hanyu Pinyin, Chinese Language Education and Research, (2010), No.11, pp.105-119.

[3] J. Lee, H. Yun, Chinese Input System using Hangeul Pronunciation, Journal of the Korea Industrial Information Systems Society, (2020), Vol.25, No.3, pp.99-110.

[4] E. Shin, D. Lee, S. Lim, Method for Inputting Chinese and Foreign Language Based on the Huminjeongeum Korean Input Keyboard, Korea Digital Publishing Research, (2016), Vol.1, No.6, pp.7-15.

[5] G. Kim, S. Hong, H. Kim, J. Byun, A Writing of Chinese Cacuminal Sounds Using Hunminjeongeum, Proceeding of the Conference of the Korean Institute of Information Scientists and Engineers, (2017), Vol.2017, No.12, pp.18981900 .

[6] J. Min, A Study on Hangul Notation Containing Chinese Tones, Journal of Koreanology, (2018), Vol.22, pp.137-170, DOI : $10.22861 /$ tiks.2018..22.137

[7] W. Jeong, A Study on the Educational Method for Chinese Language by Means of Korean Alphabets, URIMALGEUL: The Korean Language and Literature, (2009), Vol.47, pp.165-275.

[8] E. Shin, J. Choi, S. Lim, Apparatus and Method for Inputting Chinese Based on Hunminjeongeum Using Korean Input Keyboard, Journal of Korea Multimedia Society, (2020), Vol.23, No.4, pp.549-557.

[9] W. Jeong, Apparatus for Inputting Korean Character as Chinese Phonetic Transcription and Method Thereof, Korean Patent No.10-0867668, (2008)

[10] S. Beck, System and Method Displaying Hangeul Phonetic Symbols Including Chinese Language Characters using Information of Tone and Learning Method using Hangeul Phonetic Symbols Including Chinese Language Characters using Information of Tone, Korean Patent No.10-1060928, (2011)

[11] K. Kim, D. Kim, Development of Hangeul notation and Input Method for Chinese Transcription, Proceedings of the Korean Reliability Society Conference, (2015), Vol.2015, No.11, pp.5-10.

[12] H. Yun, A Diachronic Study on the Change of $/ z /(\Delta)$ in the Late Middle Korean Period, Kookmin University, Graduate School, (2009)

[13] https://newsis.com/view/?id=NISX20191111_0000825669\&cID=11011\&pID=16000, Nov 12 (2019) 